\title{
MENTAL HEALTH IN THE ELEVENTH GRADE, RUSTAQ STATE UNIVERSITY WITH SOME DEMOGRAPHIC VARIABLES
}
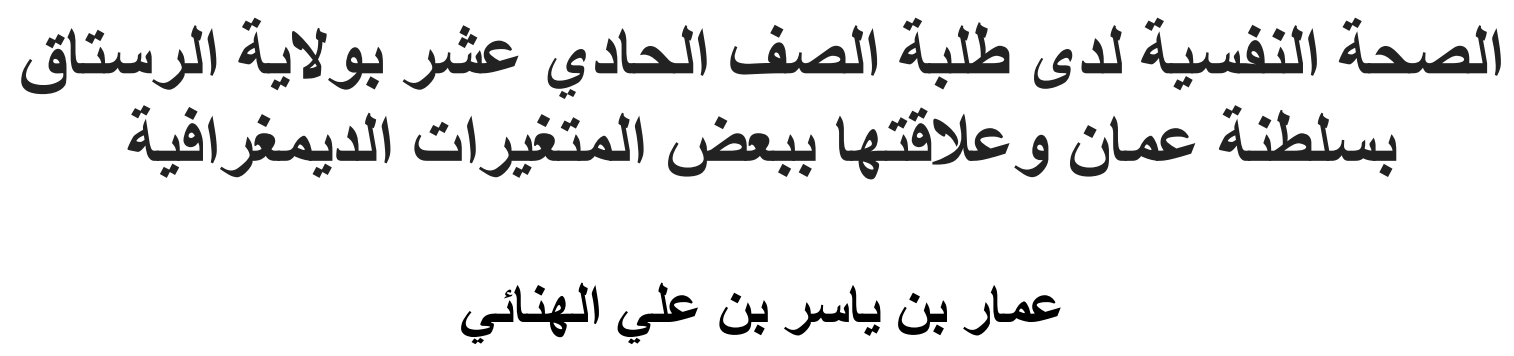

Ammar Yasir Ali Al Hinai ${ }^{1 *}$ and Prof. Dr. Mastura Badzis ${ }^{2}$

${ }^{1}$ Ph.D. Candidate at the Department of Psychology, Faculty of Education, International Islamic University Malaysia (IIUM); ammar.alhinaei@moe.om

${ }^{2}$ Prof. Dr. at the Faculty of Education, International Islamic University Malaysia (IIUM);

bmastura@iium.edu.my

${ }^{*}$ Corresponding Author

\begin{abstract}
This quantitative study discusses the mental health of eleventh grade students in the Wilayat of Rustaq, Sultanate of Oman. The problem has emerged with the existence of many economic, political and societal pressures on students in our current age, which may affect their performance, aspirations and outlook for the future, and may make attention turn to preventive and therapeutic solutions to achieve mental health. The study aims to diagnose the level of mental health of the study sample of students, and to know the differences in mental health between males and females, and the relationship of students' mental health with the monthly income of the family. The researcher used the descriptive and analytical method of collecting data according to the Mental Health Scale prepared by Abdel Khaleq (2011). Data were analyzed according to the descriptive analysis approach, T-Test and ANOVA, using SPSS software. The results of the study revealed that: the level of mental health among the students was at a high level, where the general average was (3.96) with a general standard deviation (0.96). The findings indicated that: there were no differences in the results of the study due to the variables of gender and the family monthly income.
\end{abstract}

Keywords: mental health, gender variable, monthly income.

\section{الملخص}

ناقثت هذه الدر اسة الصحة النفسية لدى طلبة الصف الحادي عشر بولاية الرسناق بسلطنة عُمان. برزت المشكلة بوجود كثير من الضغوطات الاقتصادية والسياسية و المجتمعية على الطلبة في عصرنا الحالي، مدا قد يؤثر في أداءهم وطموحاتهم ونظرتهم إلى المستقبل، وقد بجعل الاهتمام

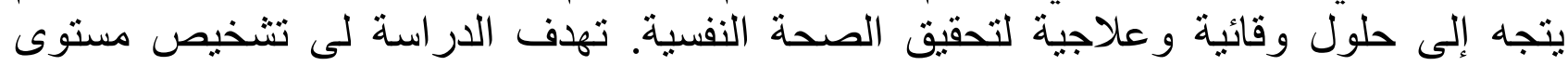
الصحة النفسية لاى عينة الدراسة من الطلبة، ومعرفة الفروقات في الصحة النفسية بين الذكور 


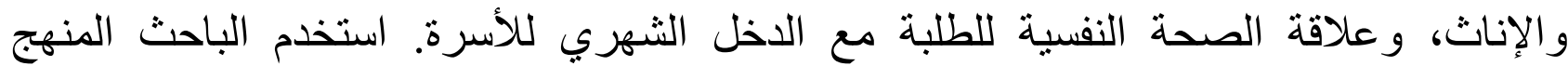

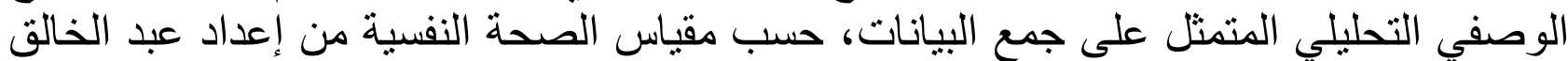

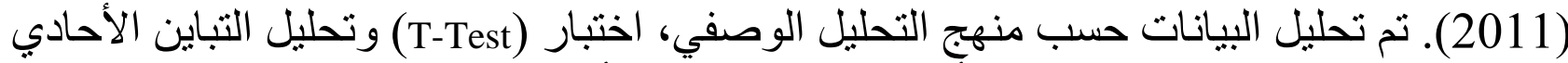

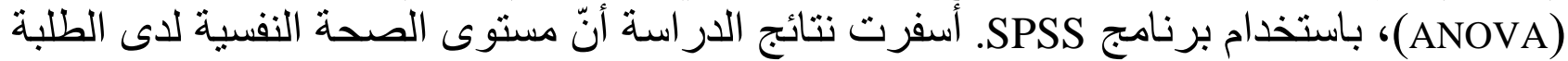

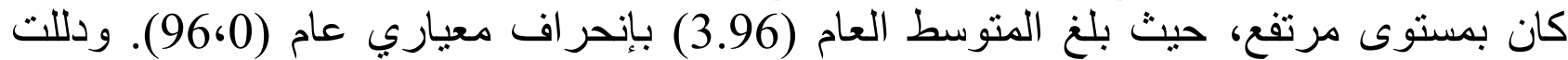

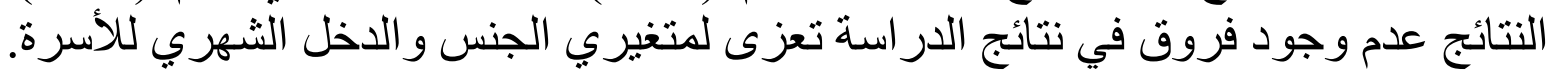
كلمات مفتاحية: الصحة النفسية، متغير الجنس، الدخل الثهري.

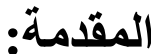

لا تخلو الحياة من المتغير ات الناشئة عن التطور السريع، وما خلفه ذلك من تأثثير بالغ في الصحة

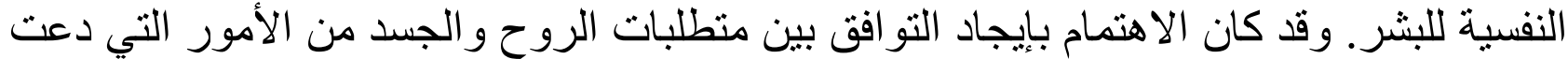

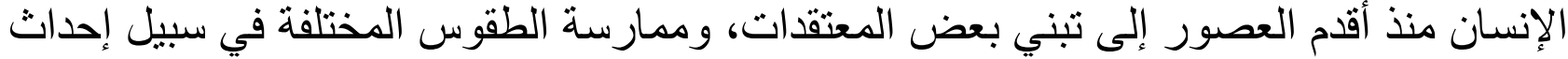

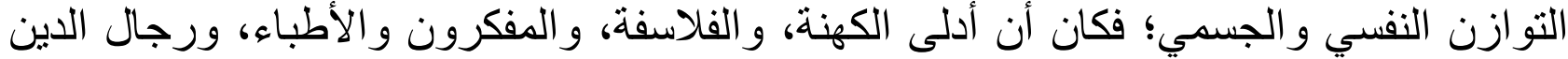
بدلو هم لتحقيق ذلك الغرض تفسير ا، و تتخيصا، و وعلاجا.

فالإنسان بوصفه مزيج من طين وروح؛ معرض للأمر اض العضوية، وكذلك النفسية بالدرجة

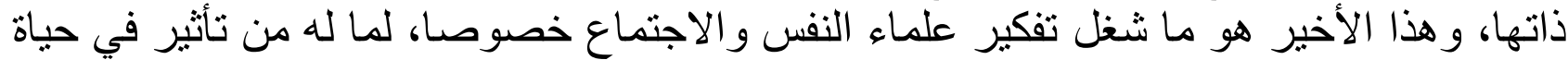

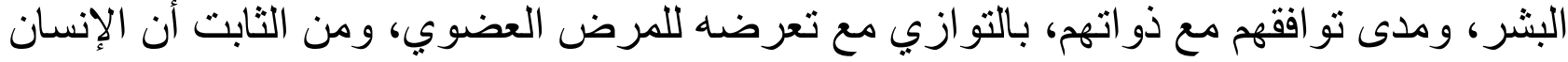

تعرف الصحة النفسية على أنها وضعية مستمرة ودائمة نسبيا، يحقق فيها الفرد نو افقه الثخصي،

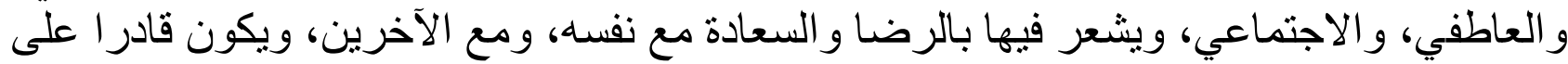

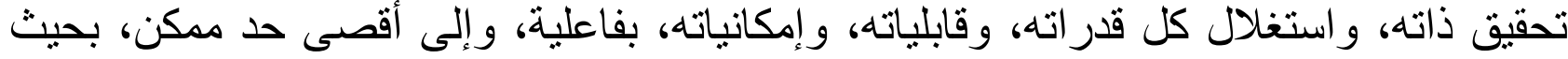

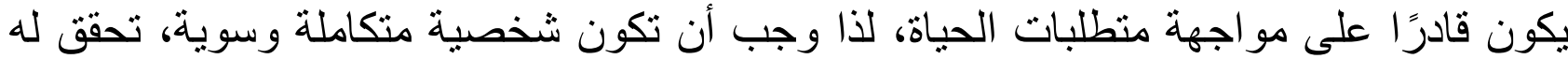

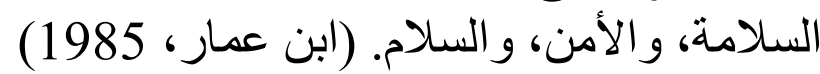

وتعرف أيضًا بأنها حالة وجدانية معرفية مركبة دائمة دواما نسبيا بأن كل مايحدث يكون طيب

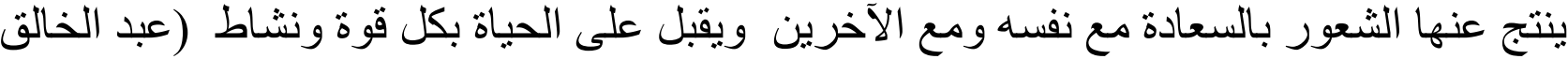

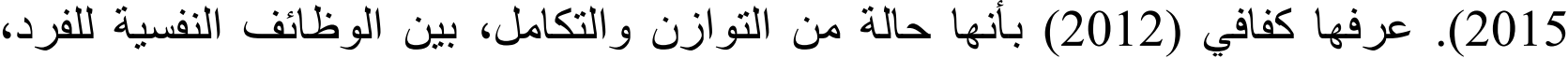

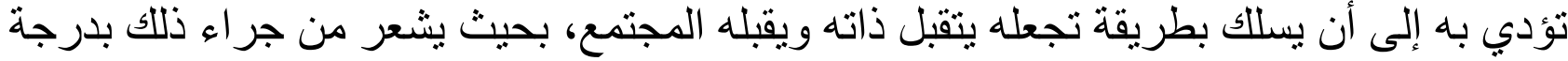
من الرضاو الكفاية.

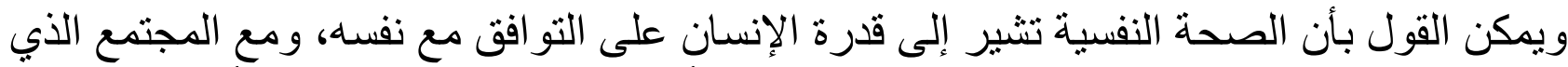

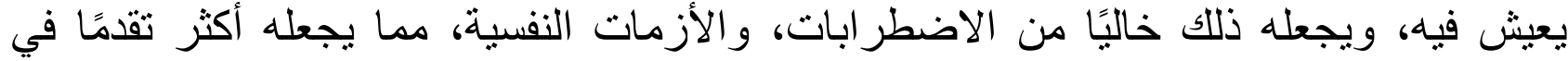
حياته، وتعاملاته مع الآخرين.

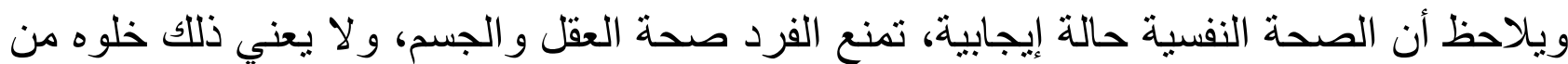

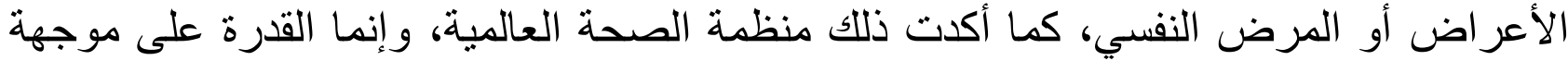
الضغوط والتعايش معها. (ابن عمار ، 1985). 


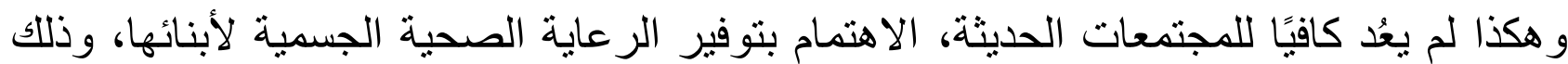

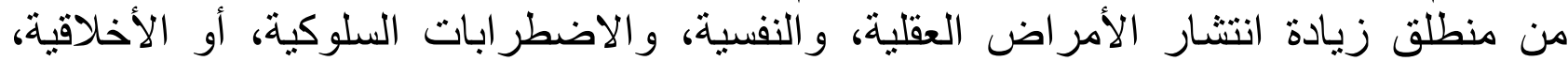

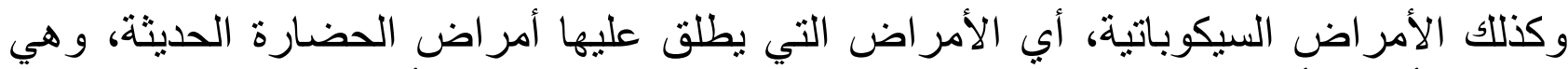

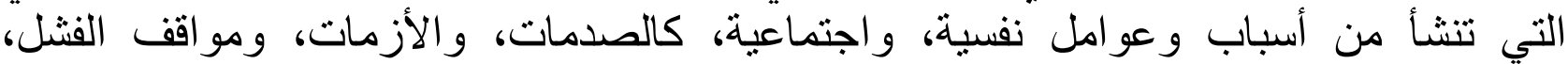

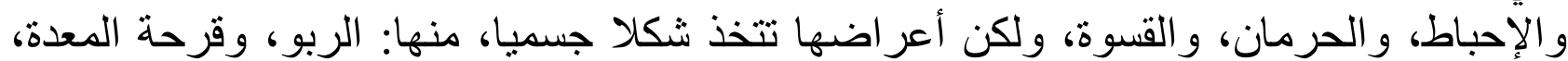

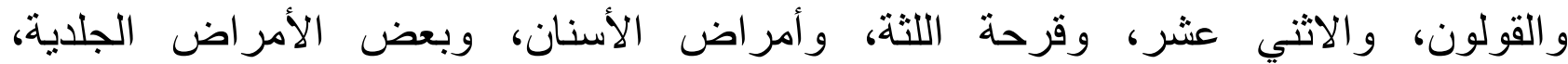

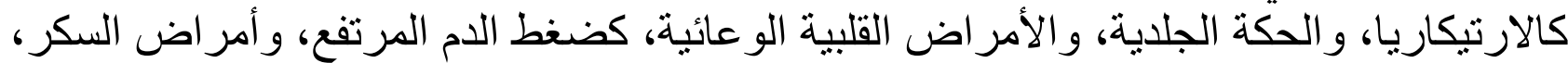

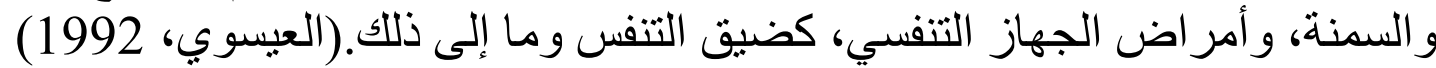

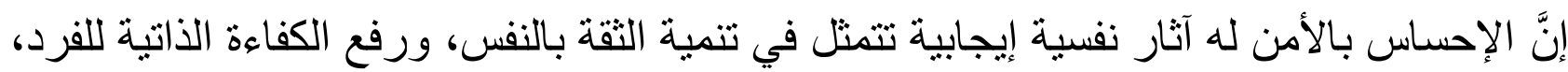

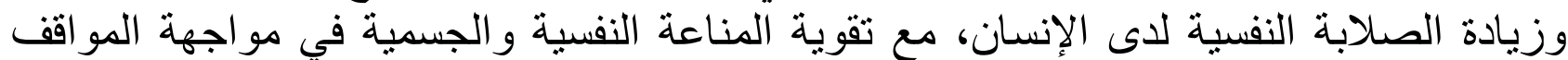

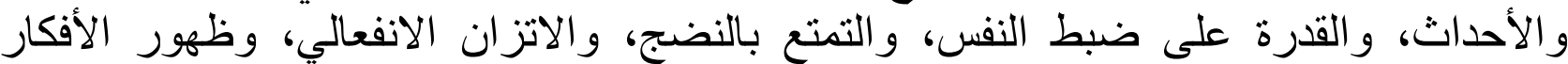

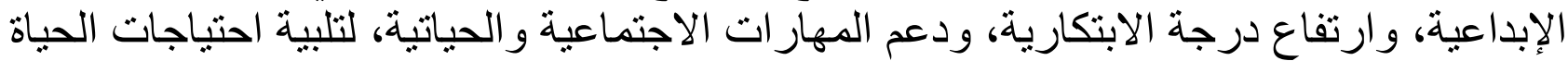

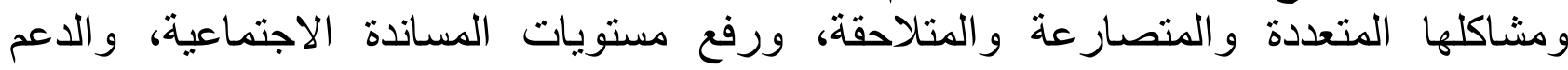

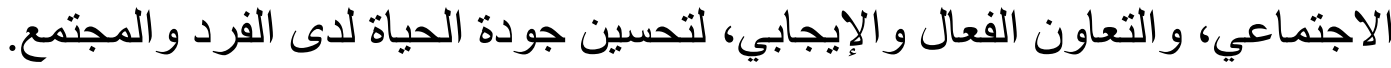

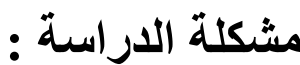

يعيش الطالب المدرسي في هذا العصر بالذات الكثير من الضغوطات الاقتصادية والسياسية

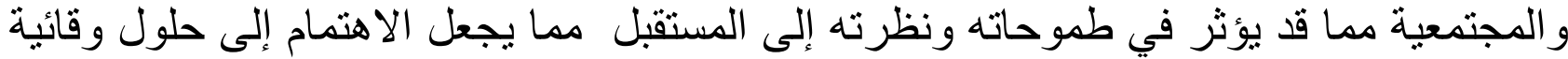

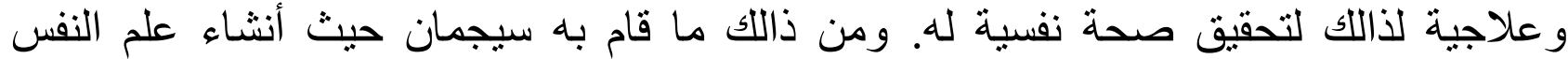

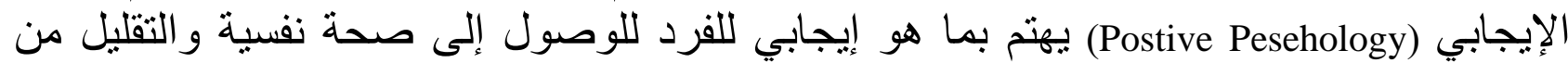
السلبيات وتحويلها إلى إيجابيات ليتخلص الفرد من الوقوع في الإضطر ابات النفسية (أبو حلاوة

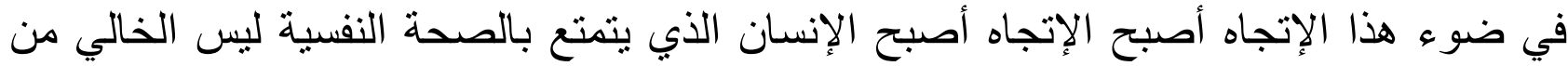

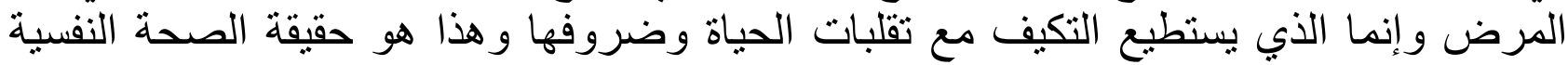

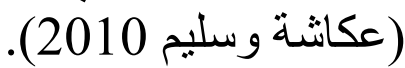

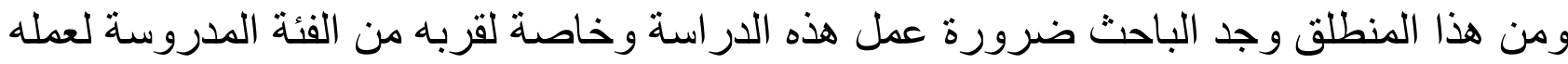
كمعلم لسنو ات ومعرفته لأهمية الجانب الإيجابي لديها لتهيئتها لبناء المستقبل بطاقة إيجابية.

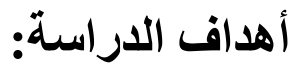
أ. تشخيص مستوى الصحة النفسية لاى عينة الدر اسة.

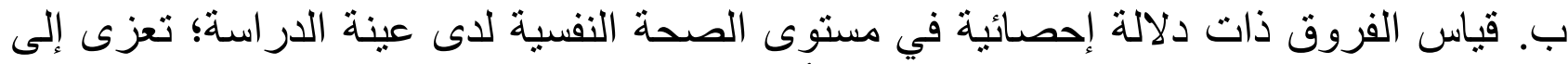
الالنغيري النوع الاجتماعي، و الدخل الثهري للأسرة.

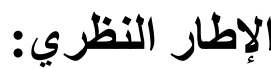

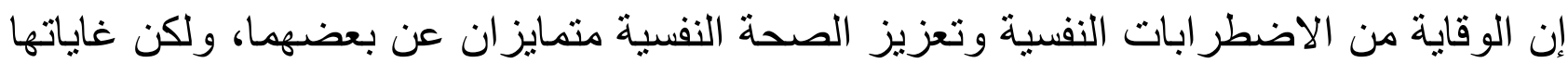

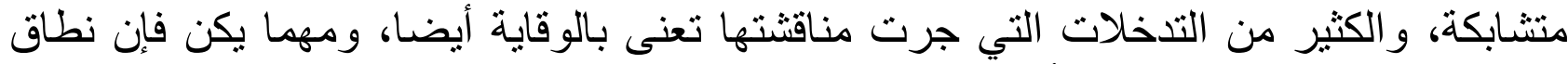

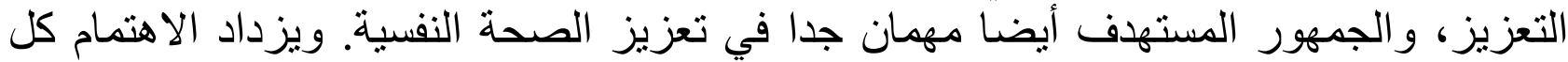


سنة وخاصة في السنو ات الأخيرة ببحث الصحة النفسية والاهتمام بها لما تم ملاحظة من الأفراد الأكثر إنجاز ا و أهتماما يتمتعون بصحة التفية اهنية مرتفعة (العمري 2012).

فالصحة النفسية مهمة بالنسبة للمجتمع بمختلف مؤسساته، لأنها تهنم بدر اسة، و علاج المشكلات ألاتهات الاجتماعية، التي تؤثر على نمو شخصية الفرد، ويمكن أن نورد بعض النقاط المتعلقة بأهمية الصحة النفسية للمجتمع:

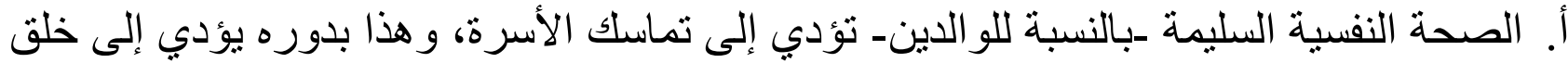
جو ملأم لنمو شخصية الطفل المنماسكة، وتجعل الأفر اد أكثر قدرة على التكيف الاجتماعي. ب. تعد الصحة النفسية ذات أهمية كبيرة في المدرسة، حيث إن العلاقة السوية بين الإدارة

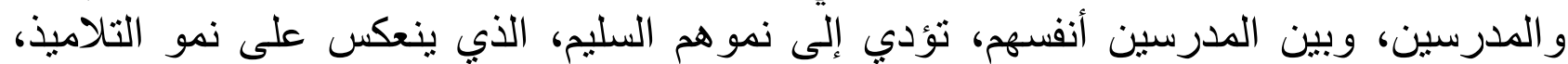
فيكون نموًا سليما، كذلك فإن العلاقة الجيدة بين المدرسة و البيت، تساعد على النمو النفسي للتلميذ. ت. الصحة النفسية مهمة للمجتمع؛ لأنها تهنم بدر اسة، وعلاج المشكلات الاجتماعية، التي تؤثر على نمو شخصية الفرد، و على المجتمع الذي بعيش فيه. ث. الصحة النفسية للمجتمع في غاية الأهمية؛ لأن المجتمع الذي بعاني من التمزق، و عدم التكامل

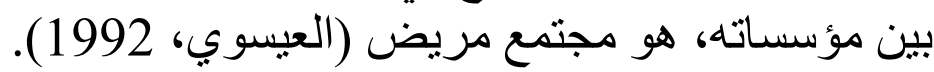
لذللك يمكننا القول بأن الصحة النفسية تؤثر بصورة كبيرة في الأفراد، والمجتمعات، من حيث تأثير ها المباثر و غير المباثر في تعامل الفرد مع غيره من الأفراد، أو تعامله كذلك مع ما يمر به من مو اقف، و وأحداث.

\section{مناهج الصحة التفسية:}

توجد ثلاثة مناهج تسعى لتحقيق الصحة النفسية و تفعيل مظاهر ها هي على النحو الآتي: أو لاـ المنهج الإنمائي (Developmental): ورذا مناسب للأسوياء و العاديين حيث بسعى على على تحقيق أقصى درجات الرضا، والسعادة، والنجاح، و التكيف أثناء دراحل النمو النهو المختلفة، لكي

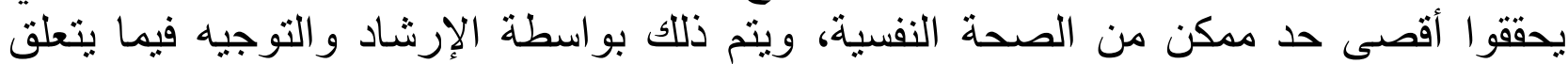

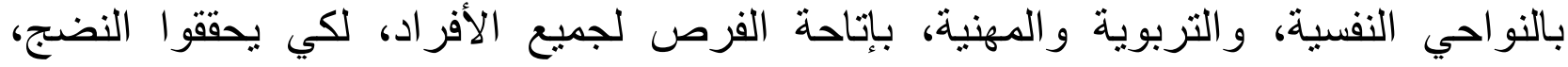
و الصحة النفسية.

ثانياــ المنهج الوقائي (preventive): وهذا المنهج يكون لجميع أفر اد المجتمع ويكون بإقامة برامج تدريبية و إرشادية تمكن الأفر اد من مواجهة أي صراع الفيسي، و وإقامة مخططات للحد من تأثيره في الوقت المناسب، من خلال عمليات التقييم، و المتابعة، و الإشادة.

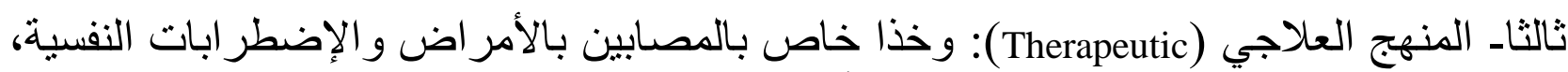
حيث يتضمن علاج الاضطر ابات النفسية، و أعر اض سوء المعالجين، ومر اكز العلاج، و العيادات

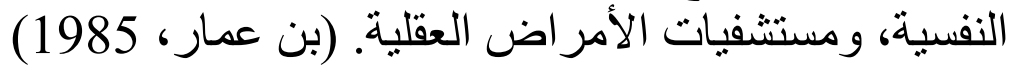

\section{نظريات الصحة التفسية:}

هنالك نظريات عدة عملت على تفسير الصحة النفسية معتمدة على أسسها التي تقوم عليها نذكر

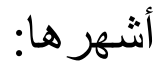


أ. النظرية التحليلية وأول من قال بها فرويد، حيث يرى حسب نظريته أن الكبت و المقاومة أكبر مؤثر للصحة النفسية وللتخلص من ذلك يجب العمل بمبدأ اللذة وتكون الأنا قادرة على التو افق بين

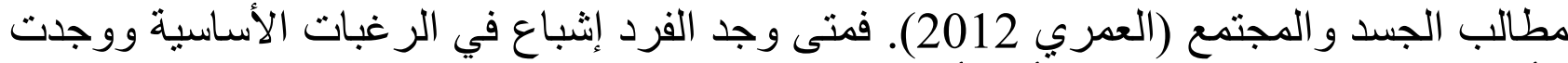
الأنا حقها وتخلصت من ضغط الأنا الأعلى تحققت الصحة النفسية لديه.

ب. النظرية السلوكية (و اطسن وسكنر):رفضت هذه النظرية تفسير نظرية التحليل النفسي للصحة

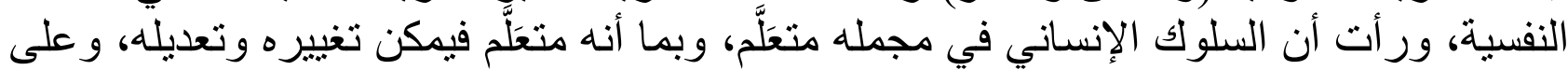

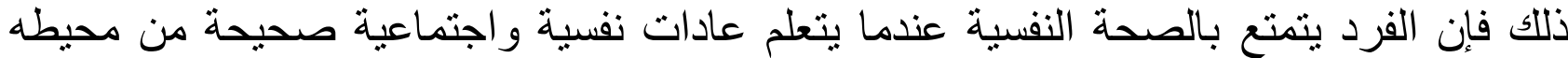
الخارجي. فتحقيق الصحة النفسية مرتبط بما بقوم به الفرد من سلوك مناسب حسب عبد الثقافة و البيئة

التي بعيش فيها (عمو من 2014).

ت. النظرية الإنسانية (ماسلو):يرى ماسلو أن الإنسان يتمتع بالصحة النفسية عندما يكون قادرا

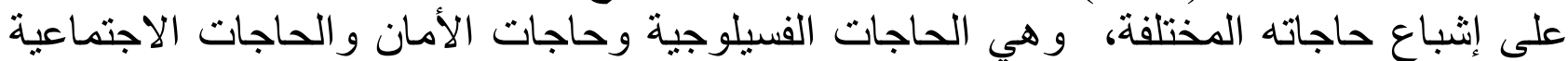
و الحاجة للتقدير و الأهم الوصول لتحقيق الذات ، و على ذللك فإن ماسلو برى بأن الإنسان قد بحتاج

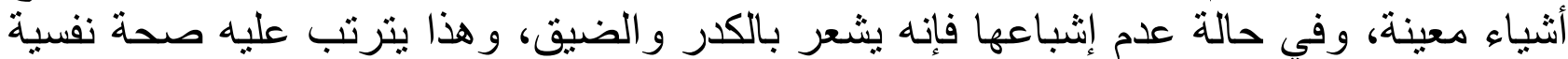

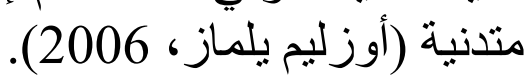

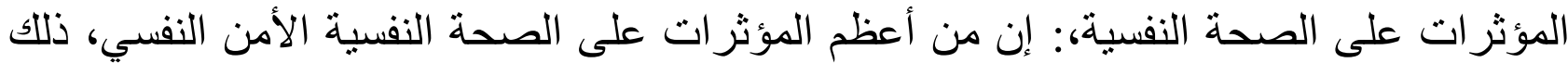

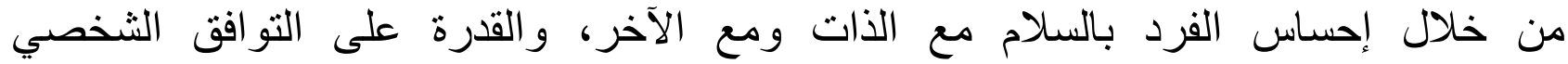

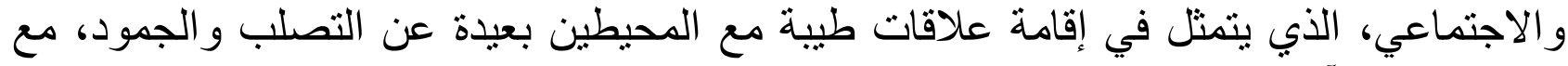

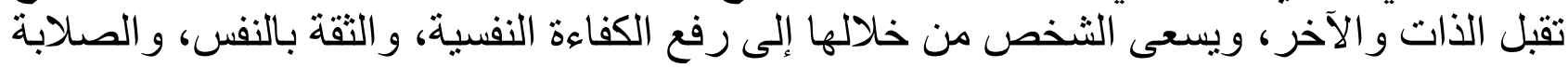
النفسية، والقدرة على العطاء، في ظل جو نفسي اجتماعي آمن تسوده الثقة المتبادلة، و الرضاء وضا، والاطمئنان (عبدالعال، 2011). ونؤكد كثير من الدراسات على أثر الصحة النفسية على الفرد والحياة بوجه عام منها دراسة

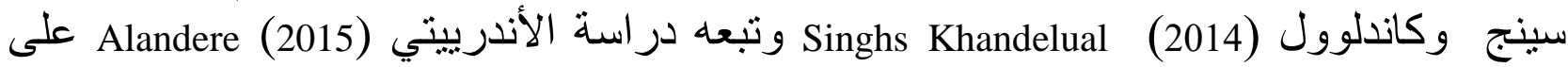
وجد علاقة إيجابية بين الصحة النفسية ومعنى الحياة وتمتع الفرد بالقوة والرفاهية (السعدية،

هنالك العديد من الدراسات التي تناولت الصحة النفسية لطلبة المدارس نذكر منها : دراسة الأخضر وفطام (2016) حيث هدفت إلى التعرف على وجود علاقة بين تقدير الذات و الصحة النفسية ، تكونت العينة من (24) طالب و (76) طالبة للمر حلة الثانوية مستحدمةا لإستبانة مقياس الزبيدي و الهزاع للصحة النفسية ومن أبرز نتائجها عدم وجود دلالة إحصائية للجنسين للصحة النفسية .

أما در اسة بني عر ابه (2017) و التي تهدف إلى در اسة أنماط التعلق و علاقته بالصحة النفسية لدى طلبة الصفين (11) و(12) وكانت العينة مكونة من (430) من الذكور و(570) من الإناتث

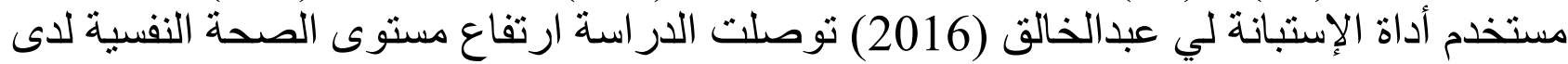
عينة الدر اسة ولا توجد فروق ذات دلالة إحصائية بين الذكور ولإناثئ. 
دراسة مونيرو (2004) Monntero و التي تهدف إلى تفعيل برنامج بالصحة النفسية وعلاقته

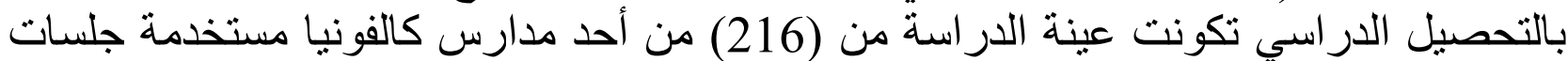

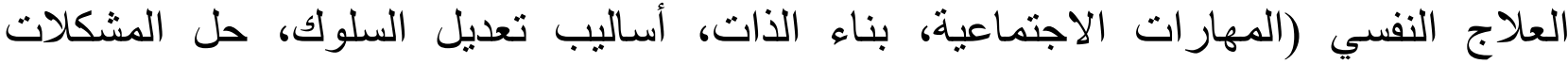

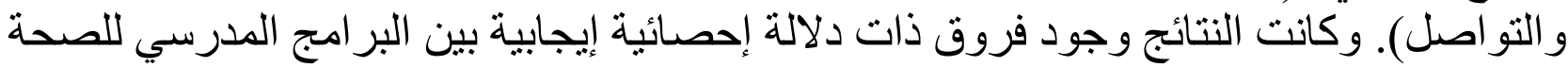

$$
\text { النفسية و التحصيل الدار واستي. }
$$

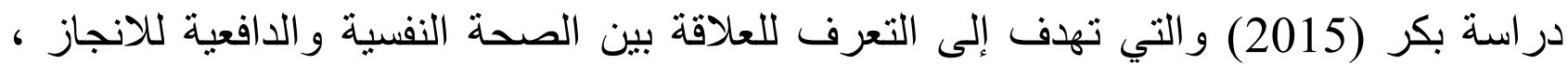
تكونت العينة من (200) طالب وطالبة جامعة الجوف وقد استخدمة مقياس الصحة النفسية

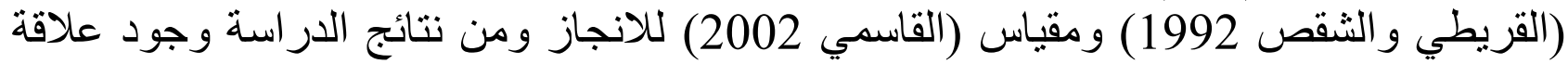

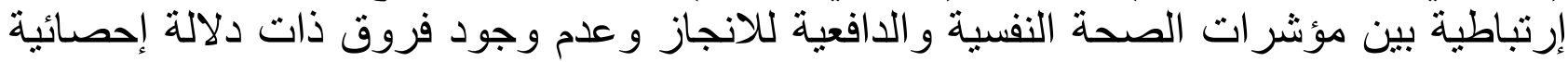
بين الأكور و الإناثة بونئ.

دراسة العمري (2012) الضغوط النفسية المدرسية وعلاقتها بالإنجاز الاكاديمي ومستوى

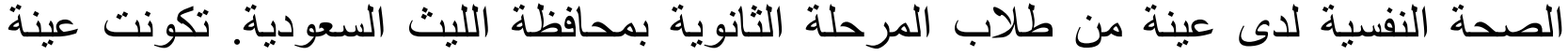

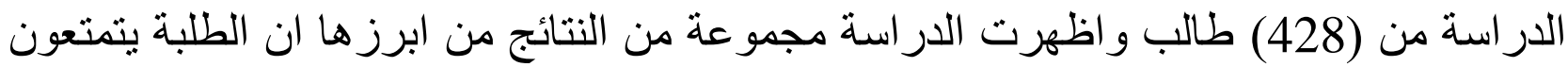

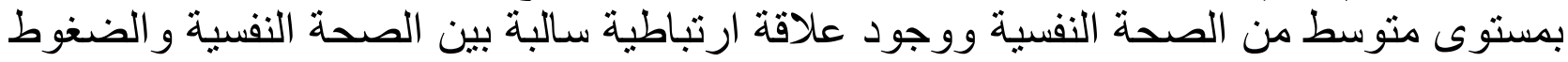
المدرسية و علاقة ارتباط موجبة بين الصحة النفية النفية والانجاز الاكاديمي.

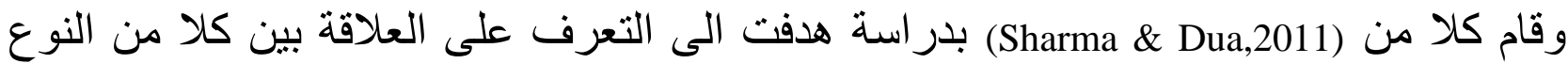

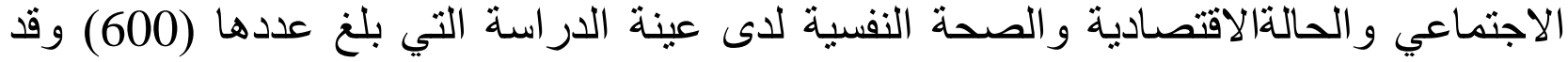

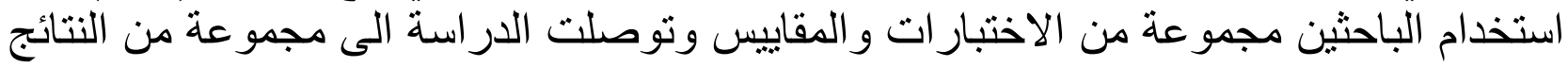

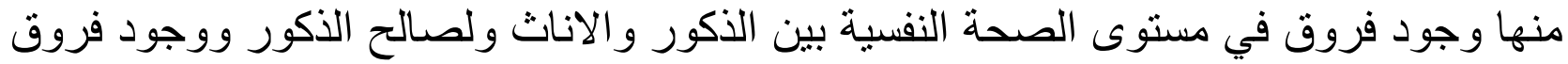

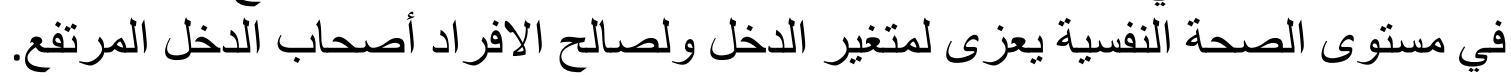
منهج الدراسة: مئري

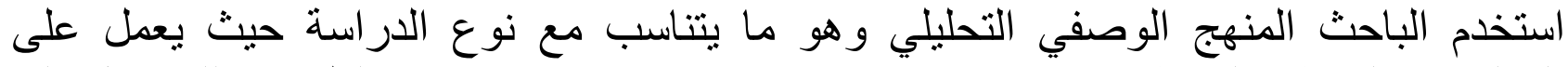

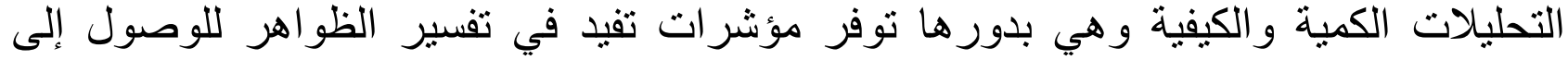

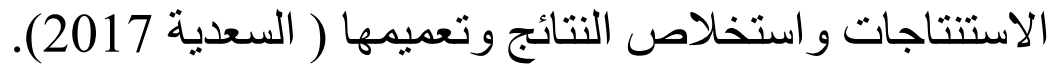

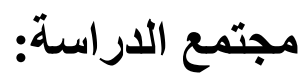
تكون مجتمع الدراسة من طلبة الصف الحادي عثر من الذكور والإناث، بمدارس ولاية الرستاق لعام 2020-2021م و البالغ عددهم (272) موز عين 128 للذكور و 144 للإناث . لإنكان. عينة الار اسة: عام

الجدول (1) توزيع عينة الدر اسة حسب متغير ات الديمو غر افية

\begin{tabular}{|c|c|c|c|}
\hline النسبة المئوية & التكرارات & المستويات & نوع المتفير \\
\hline 48.3 & 84 & ذكر & لنوع الاجتماعي \\
\hline 51.7 & 90 & انتى & \\
\hline
\end{tabular}




\begin{tabular}{|c|c|c|c|}
\hline 100 & 174 & المجموع & \\
\hline 39.1 & 68 & أقل من 500 ربال & الدخل الثهري للأسرة \\
\hline 38.5 & 67 & 1000-500 ربال & \\
\hline 22.4 & 39 & أكثر من 1000ربال & \\
\hline 100 & 174 & المجموع & \\
\hline
\end{tabular}

الثكل (1) توزيع عينة الدر اسة حسب متغير ات الديمو غر افية

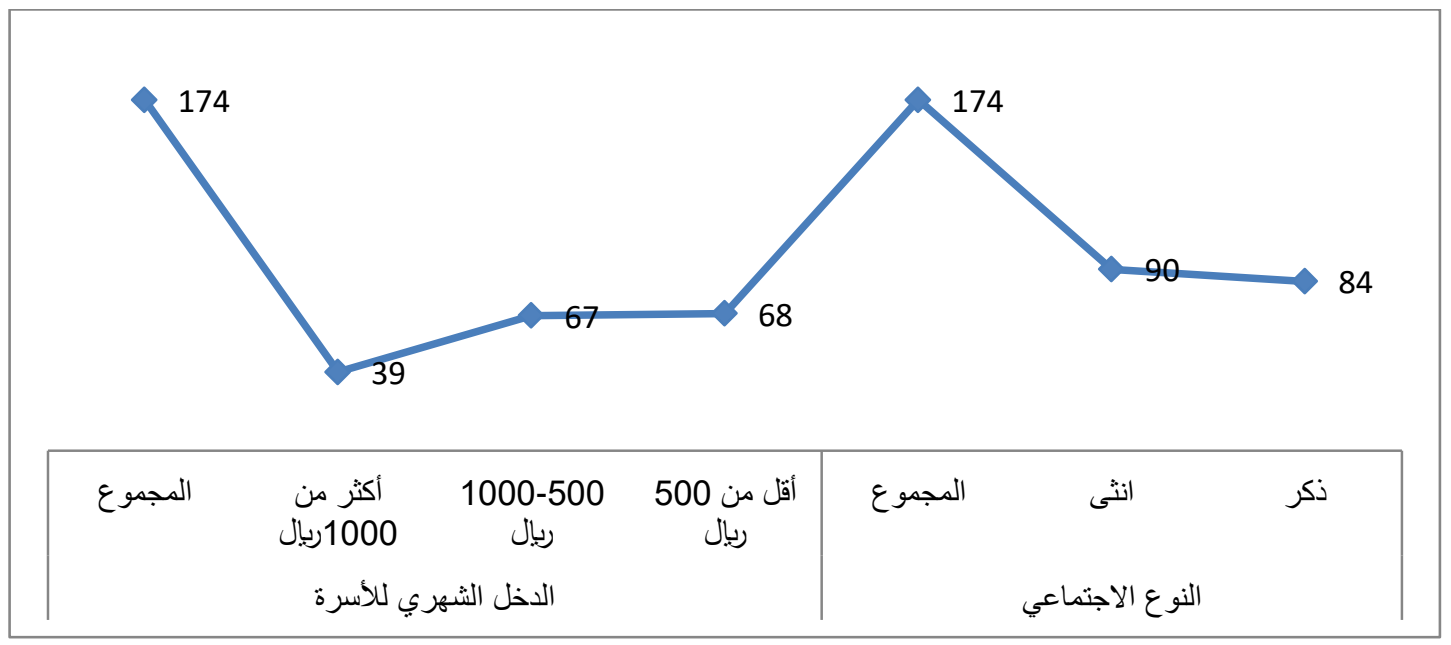

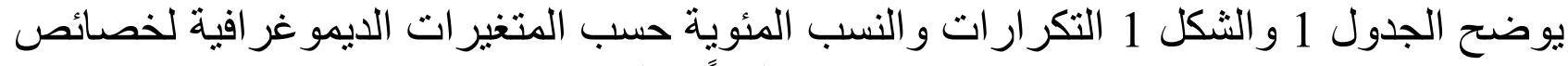

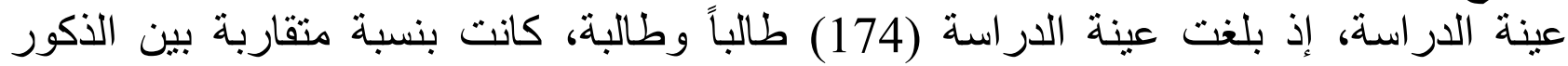

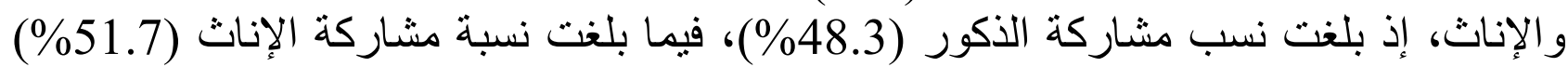
من إجمالي حجم عينة الدر اسة.

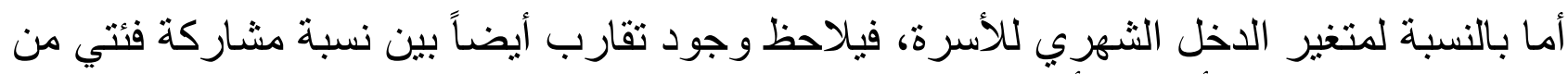

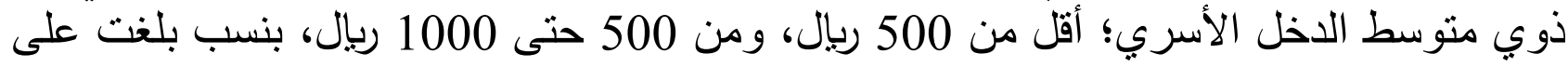

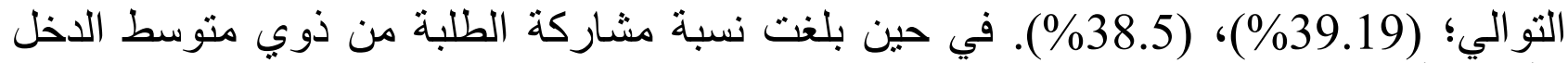

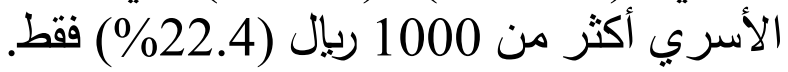
أداة الدراسة (الاستبيان): مقياس الصحة النفسية:

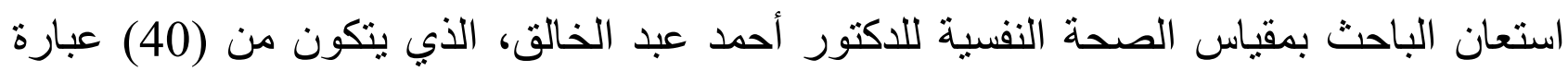

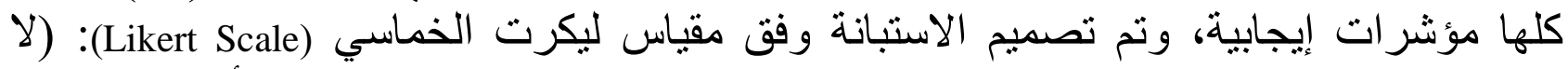

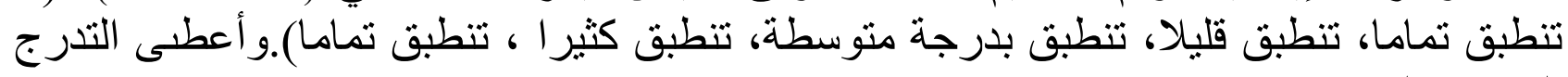

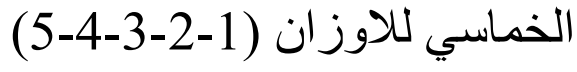

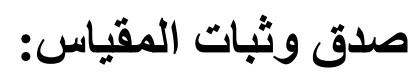

الاتساق الاخلي:Internal Consistency 


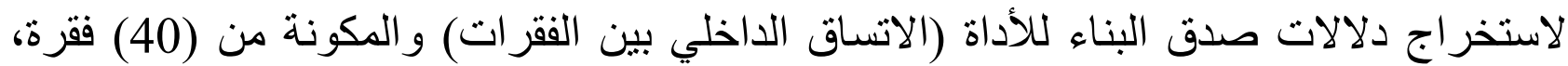

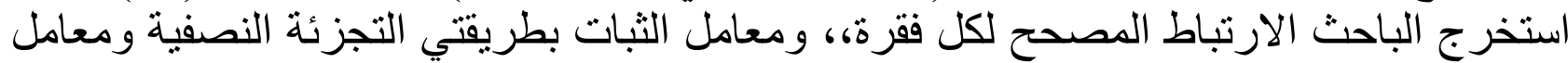

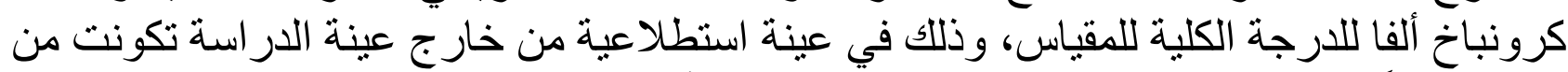

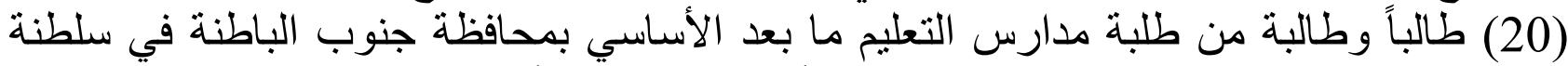

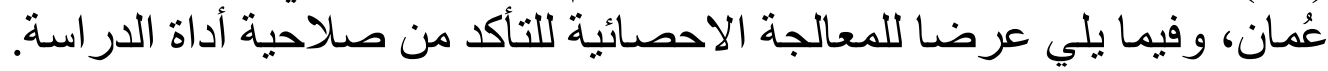
الجدول(2): معاملات الارتباط المصححة بين الفقرات

\begin{tabular}{|c|c|c|c|c|c|c|c|}
\hline الالرتحج & الفقرة & المصحح & الفقرة & المصحح & الفقرة & المصحح & الفقرة \\
\hline 0.676 & 31 & 0.583 & 21 & 0.671 & 11 & 0.382 & 1 \\
\hline 0.719 & 32 & 0.789 & 22 & 0.737 & 12 & 0.609 & 2 \\
\hline 0.691 & 33 & 0.817 & 23 & 0.638 & 13 & 0.615 & 3 \\
\hline 0.794 & 34 & 0.761 & 24 & 0.841 & 14 & 0.697 & 4 \\
\hline 0.866 & 35 & 0.518 & 25 & 0.853 & 15 & 0.77 & 5 \\
\hline 0.662 & 36 & 0.743 & 26 & 0.899 & 16 & 0.79 & 6 \\
\hline 0.759 & 37 & 0.571 & 27 & 0.775 & 17 & 0.761 & 7 \\
\hline 0.778 & 38 & 0.826 & 28 & 0.846 & 18 & 0.841 & 8 \\
\hline 0.493 & 39 & 0.875 & 29 & 0.816 & 19 & 0.794 & 9 \\
\hline 0.467 & 40 & 0.763 & 30 & 0.897 & 20 & 0.838 & 10 \\
\hline
\end{tabular}

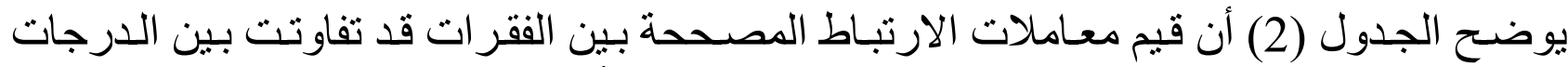

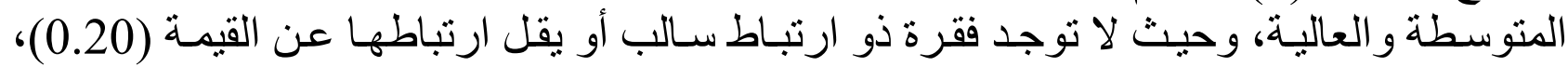

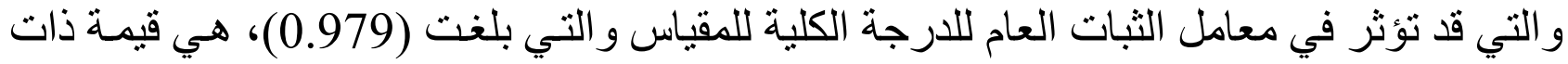

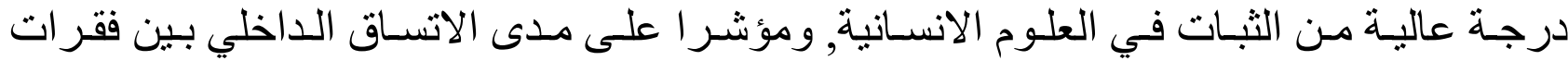

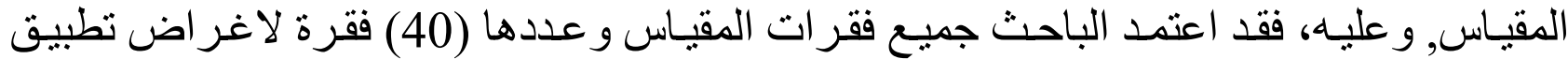
الأداة على العينة المختارة. معامل الثبات بطريقة التجزئة النصفية التهنة الجدول (3) معامل الثبات بطريقة التجزئة النصفية 


\begin{tabular}{|c|c|c|c|c|c|}
\hline (بمعامليح & التصحيح بمعامل & الارتباط بين & الجزء الثاني & الجزء الأول & المقياس \\
\hline 0.981 & 0.982 & 0.965 & الزقوجية الفر & الفقر ات الفردية & الصحة النفسية \\
\hline
\end{tabular}

يلاحظ مـن الجدول(3) أن درجـة الاتسـاق الـداخلي بـين اجابـات العينـة بطريقـة التجزئهة النصـفية

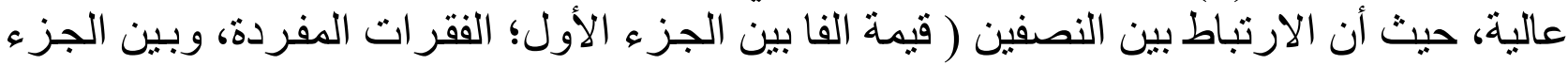

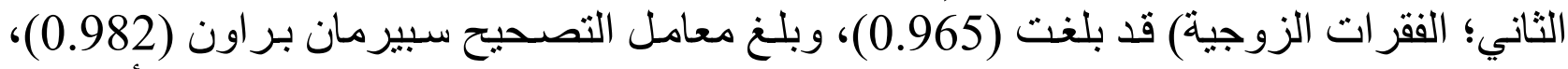

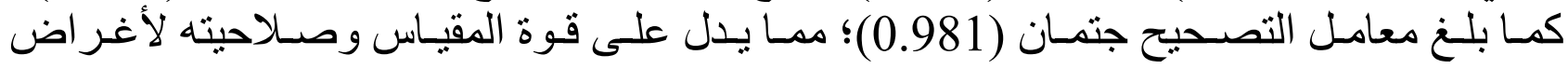
التطبيق.

\section{المعالجات الإحصائية للبيانات:}

استخدم الباحث المعالجات الاحصائية و الوصفية و التحليلية المناسبة في استخر اج النتائج لكل سؤال من أسئلة الدراسة باستخدام برنامج الرزمة الإحصائية للعلوم الاجتماعية (SPSS) على النحو التالي: 1-تـم اسـتخدام معامـل الارثبـاط كرونبـاخ الفـا ( AlphaCronbach)، للتأكد مـن صـدق وثبـات أداة الدر اسة.

2-تم حساب المتوسطات الحسابية و الانحر افات المعيارية للإجابة على السؤ ال الأول. 3-تم استخدام اختبار (T-Test) وتحليل التباين الأحادي (ANOVA)، للإجابة على السؤ ال الثاني. وقد اعتمد الباحث معيار الحكم الآتي في تفسير نتائج المتوسطات الحسابية. الجدول (4) معيار الحكم على نتائج السؤال الأول

\begin{tabular}{|c|c|}
\hline مستوى الصحة النفسية & 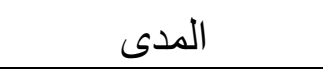 \\
\hline ضعيفة جداً & من 1 إلى 1.79 \\
\hline ضعيفة & من 1.80 إلى 2.59 \\
\hline متوسطة & من 2.60 إلى 3.39 \\
\hline عالية & من 3.40 إلى 4.19 \\
\hline عالية جداً & من 4.20 إلى 5 \\
\hline
\end{tabular}

نتائج الاراسة ومناقشتها

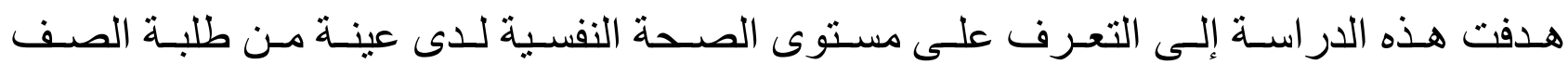

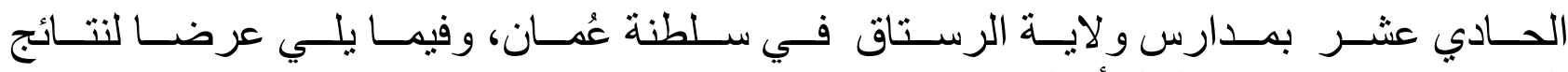
الدر اسة مرتبة حسب تسلسل أسئلتها. 


\section{أولاً: النتائج المتعلقة بالسؤال الأول، ونصه:}

"ما مستوى الصحة النفسية للى عينـة من طلبة الصفالحادي عشر ولمدارس ولايـة الرستاق في في سلطنة عُمان.

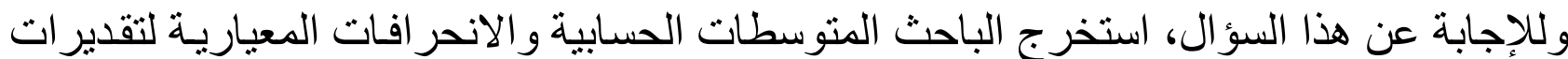

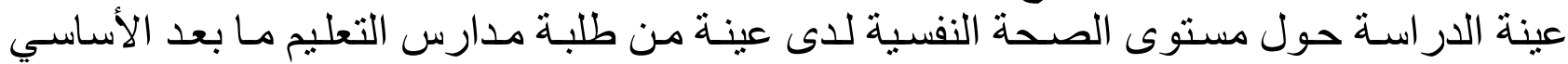

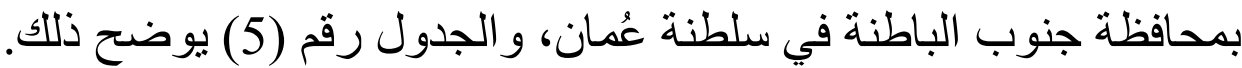
الجدول (5) مستوى الصحة النفسية لدى أفر اد العينة مرتبة تنازليا حسب المتوسطات الحسابية

\begin{tabular}{|c|c|c|c|c|c|}
\hline مستوي & المعياري & الحسابي & الفقرات & 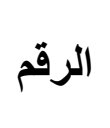 & 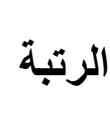 \\
\hline عالية & 1.04 & 4.30 & أنا سعيد مع أسرتي & 22 & 1 \\
\hline عدالية & 0.99 & 4.30 & حياتي لها قيمة كبيرة & 23 & 2 \\
\hline جدالية & 0.98 & 4.28 & ل لاي أمل في المستقبل & 8 & 3 \\
\hline عدالية & 1.02 & 4.27 & أشعر بالأمان & 13 & 4 \\
\hline عالية & 1.00 & 4.26 & أدرك أن حياتي لها معنى & 24 & 5 \\
\hline عالية & 0.91 & 4.25 & أثق في قدر اتي & 36 & 6 \\
\hline عالية & 1.05 & 4.20 & لديَّ خطط للمستقبل & 30 & 7 \\
\hline عالية & 0.93 & 4.17 & أنا مقتنع بنفسي & 14 & 8 \\
\hline عالية & 1.01 & 4.17 & أتوقع الأحسن & 17 & 9 \\
\hline عالية & 1.04 & 4.16 & أشعر أن مستقبلي مشرق & 19 & 10 \\
\hline عالية & 1.01 & 4.14 & أضع لنفسي أهدافا و اقعية & 40 & 11 \\
\hline عالية & 0.90 & 4.12 & أنا قادر على انجاز ما يجب عليّ القيام به & 28 & 12 \\
\hline عالية & 1.10 & 4.11 & أنظر إلى المستقبل بكل تفاؤل & 5 & 13 \\
\hline
\end{tabular}


IJASOS- International E-Journal of Advances in Social Sciences, Vol. VI, Issue 18, December 2020

\begin{tabular}{|c|c|c|c|c|c|}
\hline عالية الية & 1.02 & 4.11 & أحب الحياة & 20 & 14 \\
\hline عالية & 1.03 & 4.07 & أنا مقبل على الحياة بتفاؤل & 29 & 15 \\
\hline عالية الية & 1.16 & 4.06 & أشعر أني أحسن حالا من الماضي & 26 & 16 \\
\hline 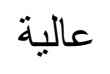 & 0.95 & 4.05 & أعرف إمكاناتي & 38 & 17 \\
\hline 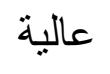 & 1.04 & 4.04 & أنا راض عن نفسي & 4 & 18 \\
\hline 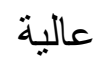 & 1.00 & 4.02 & ل ل لدي إر ادة قوية & 16 & 19 \\
\hline عالية الية & 1.00 & 4.01 & معنو ياتي مرتفعة & 15 & 20 \\
\hline عالية الية & 1.04 & 4.00 & أشعر بالر احة & 18 & 21 \\
\hline 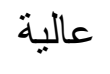 & 1.12 & 3.99 & أفكاري عن نفسي إيجابية & 35 & 22 \\
\hline 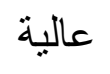 & 1.03 & 3.98 & أثنعر أن حياتي تسير في الاتجاه الصحيح & 37 & 23 \\
\hline 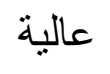 & 0.98 & 3.97 & أستمتع بوجودي مع الآخرين & 39 & 24 \\
\hline عالية الية & 0.97 & 3.95 & ثقتي بنفسي كبيرة & 2 & 25 \\
\hline عالية & 1.04 & 3.95 & تبدو لي الحياة جميلة & 10 & 26 \\
\hline عالية ع الية & 1.09 & 3.92 & أستمتع بحياتي & 6 & 27 \\
\hline 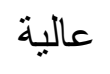 & 1.07 & 3.83 & أستطيع أن أسترخي & 34 & 28 \\
\hline 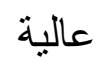 & 1.03 & 3.82 & أنا مملو ء بالحيوية & 9 & 29 \\
\hline 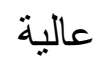 & 1.17 & 3.80 & أشعر بالسعادة & 7 & 30 \\
\hline 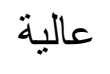 & 1.10 & 3.80 & أنا منسجم مع من حولي & 21 & 31 \\
\hline 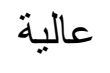 & 1.02 & 3.78 & أنا ناجح في حياتي & 3 & 32 \\
\hline 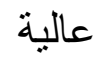 & 1.05 & 3.78 & أنا شخص نشيط & 33 & 33 \\
\hline 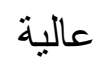 & 1.06 & 3.70 & أشعر أن الحياة مملوءة بالمتع & 12 & 34 \\
\hline 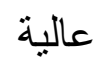 & 1.05 & 3.66 & لدي القدرة على مو اجهة الأزمات & 11 & 35 \\
\hline 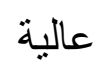 & 1.19 & 3.57 & أشعر أني محظوظ في حياتي & 27 & 36 \\
\hline 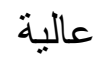 & 1.12 & 3.54 & أستطيع التغلب على مشاعر القلق & 31 & 37 \\
\hline
\end{tabular}




\begin{tabular}{|c|c|c|c|c|c|}
\hline عالية & 1.13 & 3.49 & مز اجي معتدل & 32 & 38 \\
\hline متوسطة & 1.11 & 3.37 & انفعالاتي متوازنة & 25 & 39 \\
\hline متوسطة & 1.12 & 3.36 & أشعر بالانشر اح & 1 & 40 \\
\hline عالية & 0.71 & 3.96 & \multicolumn{3}{|c|}{ مقياس الصحة النفسية ككل } \\
\hline
\end{tabular}

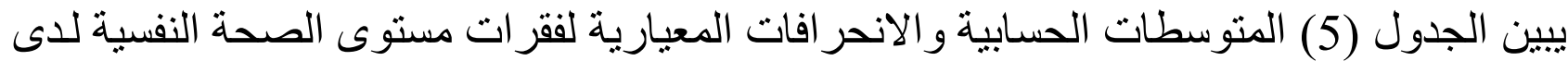

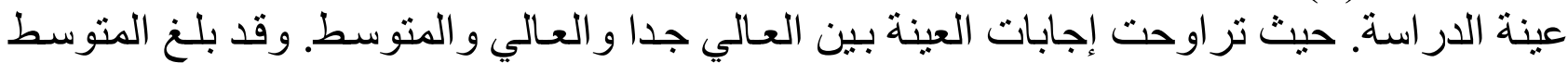

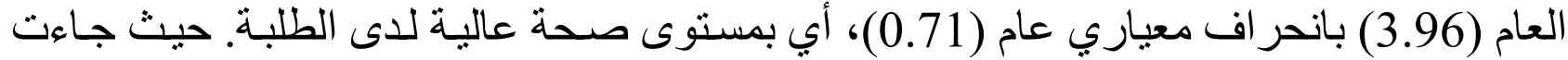

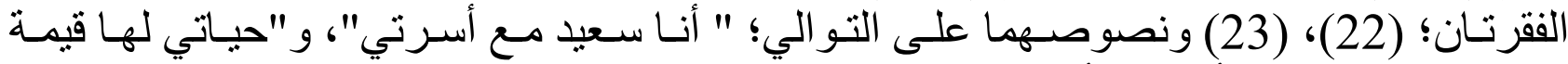

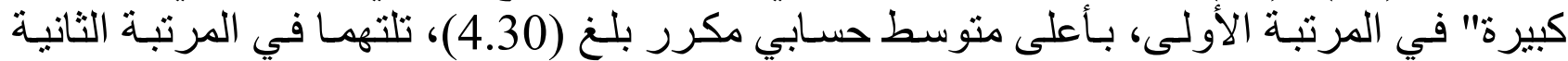

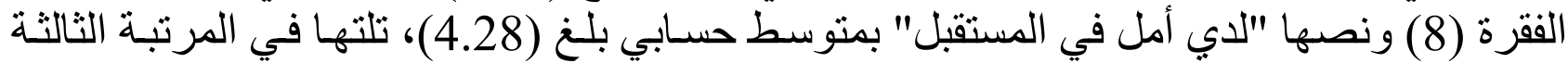

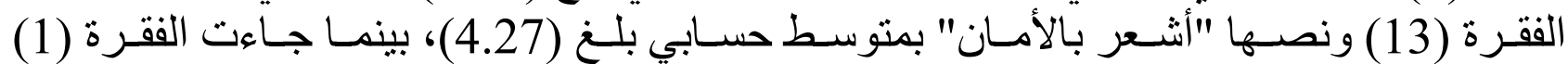
ونصـها" أثـعر بالانشـر اح" في المرتبـة الأخيرة، وبدرجـة متوسطة حيـث بلـغ المتوسط الحسـيابي

ثانياً: النتائج المتعلقة بالسؤال الثاني، ونصه: " هل توجد فروق ذات دلالـة إحصـائية في مستوى الصحة النفسية لدى عينـة الدر اسـة تعزى إلى الصى

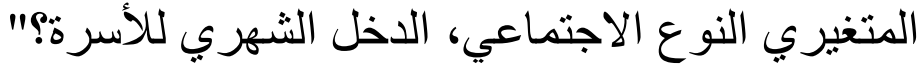

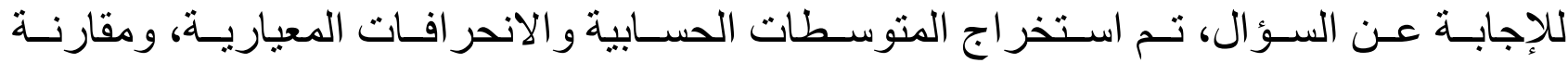

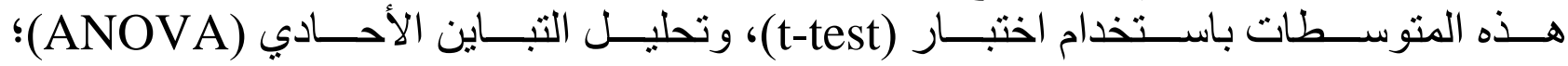

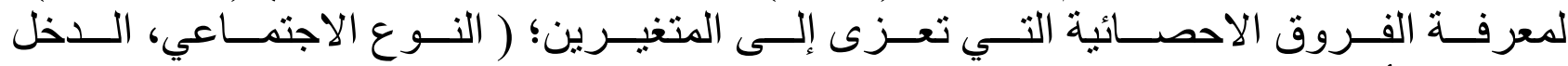
الثهري للأسرة) على النحو الآتي. أولاً: متغير " التوع الاجتماعي"

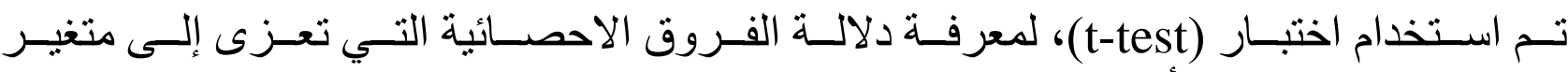
النوع الاجتماعي (ذكر/ أنثى). الجدول 6: اختبار (t-test) لدلالة الفروق الاحصائية تبعاً لمتغير النوع الاجتماعي

\begin{tabular}{|c|c|c|c|c|c|c|}
\hline الإحصائية الالة & قيمة (ت) & الانحراف & الحستوسطي & ن= العدد & النوع & المقياس \\
\hline \multirow[t]{2}{*}{0.714} & 0.367 & 0.69 & 3.94 & 84 & 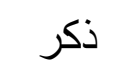 & \multirow[t]{2}{*}{ مستوى الصحة النفسية } \\
\hline & & 0.74 & 3.98 & 90 & أنثى & \\
\hline
\end{tabular}

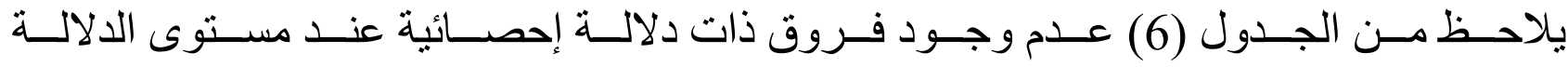




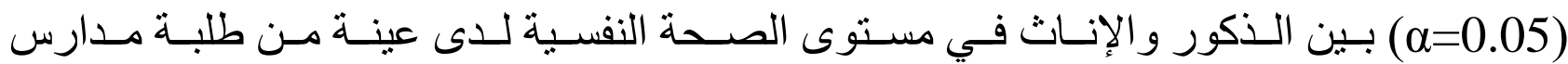
التعليم ما بعد الأساسي بمحافظة جنوب الباطنة في سلطنة عُمان.

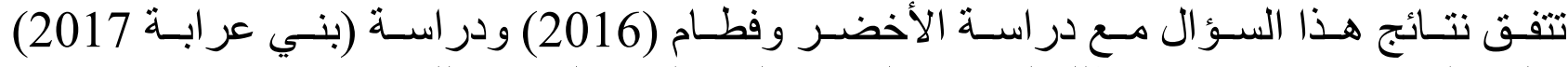
و الكندية (2020) وقد يرجع ذللك لتساوي الحقوق المقدمة من المجتمع للجنسين.

ثاتياً: مغير " الاخل الثهري للأسرة" تم استخراج المتوسطات الحسابية والانحر افات المعيارية؛ لمعرفة أثر متغير الدخل الثهري للأسرة، و الجدول (7) يوضح ذلاجن.

الجدول (7) المتوسطات الحسابية والانحر افات المعيارية لأثر متغير الدخل الثهري للأسرة

\begin{tabular}{|c|c|c|c|}
\hline الانحراف المعياري & المتوسط الحسابي & ن=174 العدد & الاخل الشهري للأسرة \\
\hline 0.82 & 3.89 & 68 & أقل من 500 ربال \\
\hline 0.67 & 3.93 & 67 & 1000-500 ربال \\
\hline 0.58 & 4.13 & 39 & أكثر من 1000ربال \\
\hline 0.71 & 3.96 & 174 & الكلي \\
\hline
\end{tabular}

يبين الجدول رقم (7) تبيانا منقارباً في المتوسطات الحسابية و الانحر افات المعيارية لتقدير ات عينة

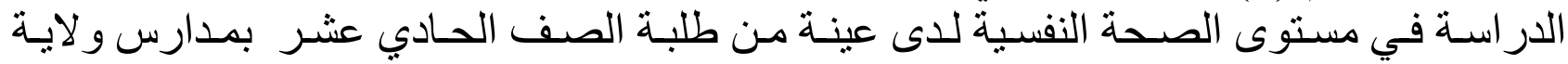
الرستاق في سلطنة عُمان. تعزى لمتغير الدخل الثهري للأسرة.

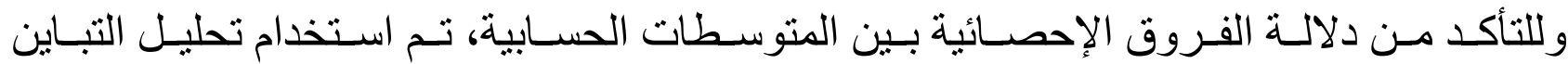

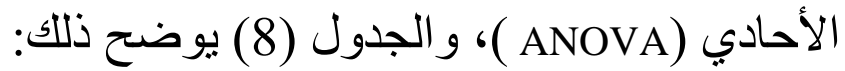

الجدول (8) تحليل التباين الأحادي (ANOVA) لأثر متغير الدخل الثهري للأسرة

\begin{tabular}{|c|c|c|c|c|c|c|}
\hline الإحصائية & قيمة ف & المربعات & الحرية & المربعوع & المصدر & المقياس \\
\hline \multirow[t]{3}{*}{0.236} & 1.456 & 0.739 & 2 & 1.477 & بين & \multirow{3}{*}{ الصحة النفسية } \\
\hline & & 0.507 & 171 & 86.781 & داخل & \\
\hline & & & 173 & 88.258 & الكلي & \\
\hline
\end{tabular}

يلاحظ من الجدول رقم (8) عدم وجود فروق ذات دلالة إحصائية عند مستوى الدلالة (م=0.05) 
في تقديرات عينة الدراسة حول مستوى الصحة النفسية لدى عينة الدراسة تعزى لمتغير الدخل الثَهري للأسرة.

واختلفت نتائج السؤال مع دراسة (Sharma \& Dua,2011) وقد يعود السبب إلى وجود التكافل الاجتماعي و اللحمة الأسرية في الو لاية لطبيعتها الجبلية.

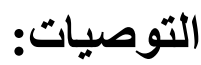

- عل بر امج توعوية للطلبة تمكنهم من التعايش من تغير ات الحياة . - تدريب المعلمين على معرفة كيفية تقيم الطلاب نفسيا. - توفير المناخ المناسب في المدارس الذي يساعد على تتمية الصحة النفسية لدى الطلبة - عل در اسات مختلفة ولفئات مختلفة في سلطنة عمان

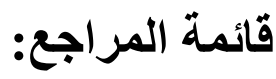
ابن عمار، مححـ. (1985). الثقافة و الصحة النفسية للثباب. المجلة العربية للتقافة: المنظمة العربية

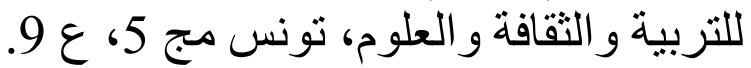
بني عر ابة ،هلال بن خلفان بن ناصر. (2017. أنماط التعلق و علاقتها بالصحة النفسية لدى طلبة ولنة الصفين العاثر والحادي عشر بمدي بمدارس محافظة شمال الثرقية. رسالة ماجستير غير

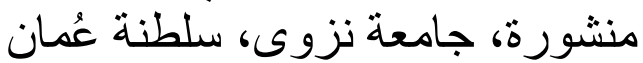
السعدية ميا سعيد سالم. (2017). الصحة النفسية وعلاقتها بمعنى الحياة لدى طلبة الصف الحادي عشر في محافظة جنوب الباطنة، رسالة ماجستير، جامعة نزوى، سلطنة عُمان. شريف. سعود، ناهد. (2016). الفروق في الصحَّة النفسيَّة وفق نمطيّ الميول المهنيَّة الواقعي

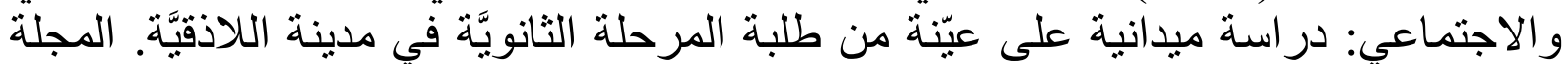
الدولية التربوية المتخصصة ـ دار سمات للار اسات و الأبحاث، 5 (10)، 314-328. عبدالخالق، أحمد. (2015). أصول الصحة النفسية. الإسكندرية: دار المعرفة الجامعية. العمري، مرزوق أحمد عبدالمحن. (2012). الضغوط النفسية المدرسية وعلاقتها بالإنجاز الاكاديمي ومستوى الصحة النفسية لاى عينة من طلاب المرحلة الثانوية بمحافظة الليث. رسالة ماجستير غير منشورة، كلية التربية، جامعة أم القرى.

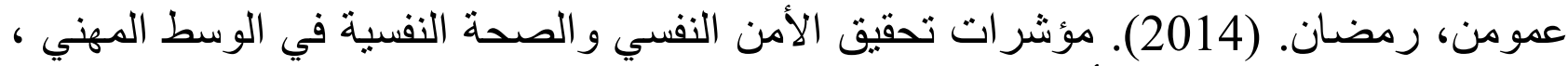

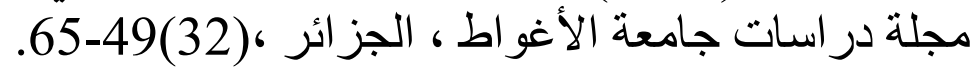

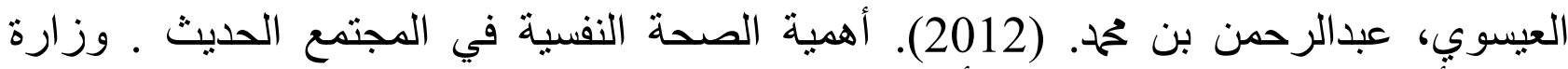
الأُوقاف و الثؤون الإسلامية، الأردن.

قويدري، الأخضر وفطام، جمال. (2016). تقدير الذات وعلاقته بالصحة النفسية لدى عينة من الأنة

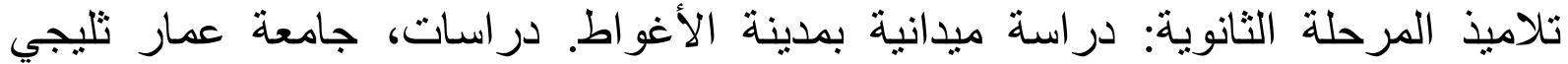

$$
\text { بالأغو اط، الجز ائر }
$$




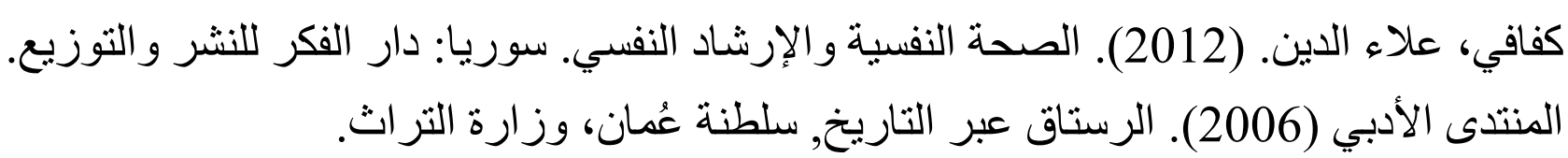

\section{ARABIC REFERENCES IN ROMAN ALPHABET}

Abn Eamar, Muhmd. (1985). Althaqafat Walsihat Alnafsiat Lilshabab. Almajalat Alearabiat Lilthaqafat: Almunazamat Alearabiat Liltarbiat Walthaqafat Waleulumi, Tunis Mja 5, E 9.

Bani Earabat ,Hilal Bin Khlfan Bin Nasir. (2017. 'Anmat Altaealuq Waealaqataha Bialsihat Alnafsiat Ladaa Tlbt Alsafin Aleashir Walhadi Eshr Bimadaris Muhafazat Shamal Alsharqi. Risalat Majstyr Ghyr Manshuratin, Jamieatan Nazwaa, Saltanat Euman

Alsiediat Maya Saeid Salum. (2017). Alsihat Alnafsiat Waealaqatuha Bimaenaa Alhayat Ladaa Tlbt Alsafi Alhadii Eshr Fi Muhafazat Janub Albatinati, Risalat Majstir, Jamieat Nazwaa, Saltanat Eunman.

Sharif. Sueud, Nahd. (2016). Alfuruq Fi Alshat Alnfsyat Wfq Nmty Almuyawil Almhnyat Alwaqieii Walaijtimaei: Dirasat Maydaniatan Ealaa Eynt Min Tlbt Almarhalat Althanwyat Fi Madinat Alladhqya. Almajalat Alduwaliat Altarbawiat Almutakhasisat - Dar Simat Lildirasat Wal'abhathi, 5 (10), 314-328.

Eibdalkhaliq, 'Ahmud. (2015). 'Usul Alsihat Alnafsiatu. Al'iiskandariat: Dar Almaerifat Aljamieiat.

Aleamriu, Marzuq 'Ahmad Eabdalmihsin. (2012). Aldughut Alnafsiat Almadrasiat Waealaqatuha Bial'iinjaz Alakadimi Wamustawaa Alsihat Alnafsiat Ladaa Eayinat Min Tullab Almarhalat Alththanawiat Bimuhafazat Alliyth. Risalat Majstayr Ghyr Manshuratin, Kuliyat Altarbiati, Jamieatan 'Am Alquraa.

Eumuman, Ramadan. (2014). Muashirat Tahqiq Al'amn Alnafsii Walsihat Alnafsiat Fi Alwasat Almahnii , Majalat Dirasat Jamieat Al'aghwat, Aljazayir ,(32)49-65.

Aleisawi, Eabdalrhamin Bin Mahmud. (2012). 'Ahamiyat Alsihat Alnafsiat Fi Almujtamae Alhadith . Wizarat Al'awqaf Walshuwuwn Al'iislamiati, Al'urdunn.

Quidri, Al'akhdar Wafatam, Jamal. (2016). Taqdir Aldhdhat Waealaqatih Bialsihat Alnafsiat Ladaa Eayinat Min Talamidh Almarhalat Alththanuiat: Dirasat Maydaniat Bimadinat Al'aghwati. Dirasati, Jamieat Eammar Thlyji Bial'aghwati, .Aljazayir

Kafafi, Eala' Aldiyn. (2012). Alsihat Alnafsiat Wal'iirshad Alnafsi. Suria: Dar Alfikr Lilnashr Waltawzie.

Almuntadaa Al'adbuy (2006). Alrusitaq Eabr Altarykh, Saltanat Euman, Wizarat Altarath.

\section{REFERENCES}

Sharma, Namita \& Dua, Radha. (2011), Gender \& Economic Status Matter in Mental Health of Adolescents. Journal on Educational Psychology, 4 (3), $45-.05$ 